\title{
On Intergenerational Transmission of Domestic Violence: Pollak Revisited
}

\author{
Şevket Alper Koç* \\ Kocaeli Uniiversity
}

\author{
Hakkı Cenk Erkin*** \\ Kocaeli Uniiversity
}

\begin{abstract}
We offer a reformulation of Pollak's model of domestic violence by incorporating a feedback relationship between the prevalence of wife abuse in a society and men's proclivity to violence at home and the impact of higher education. College educated women are significantly less likely to experience domestic violence and more likely to leave abusive partners. Moreover, husbands might become less hesitant to act violently if physical aggression were an accepted and pervasive part of family life in a society. Therefore, there might be a two-way relationship between the level of violence in the community and the level of violence at home.
\end{abstract}

Keywords: Domestic violence, gender inequality, education.

\section{Aile İçi Şiddetin Nesiller Arası Aktarımı: Pollak Modelinin Yeniden İncelenmesi}

\section{Özet}

Bu makalede Pollak'ın aile içi şiddetin nesiller arası aktarımı modeli iki yönde geliştirilmiştir. İlk olarak, yükseköğrenimin aile içi şiddet üzerindeki etkisi modele eklenmiştir. Aile içi şiddet üzerine yapılan çalışmalarda tutarlı olarak kadının ya da erkeğin üniversite mezunu olmasının şiddeti önemli ölçüde azalttığı bulunmuştur. İkinci olarak, erkeklerin eşlerine karşı şiddet kullanma olasılığının aile içi şiddetin toplumdaki yaygınlığı ile doğru orantılı değiştiği varsayımı üzerinde durulmuştur.

Anahtar kelimeler: Aile içi şiddet, cinsiyet eşitsizliği, e ğitim.

Şevket Alper Koç is an Assistant Professor in the Department of Economics at Kocaeli University, 41380, Kocaeli, Turkey. E-mail: alperkoc@kocaeli.edu.tr

** Hakk1 Cenk Erkin is an instructor in the Department of Economics at Kocaeli University, 41380, Kocaeli, Turkey. E-mail: cenkerkin@kocaeli.edu.tr 
$\mathrm{D}$ omestic violence is a serious social problem that is afflicting most, if not all, cultures. ${ }^{[1],[2]}$ Victims of domestic violence suffer from a wide range of health problems including bruises, fractures, chronic pain syndromes, gynecological disorders, depression, post-traumatic stress disorder, sexually transmitted diseases and unwanted pregnancy (Krug et al., 2002). At its extreme, domestic violence precedes homicide or suicide.

Domestic violence also creates significant costs for the society. Direct costs are related expenditures for health care, social services and law enforcement. Indirect costs, which are thought to be significantly larger because of their long-term effect on economic growth, include many diverse effects of violence such as lower income resulting from job loss, decreased productivity in the workplace, lower labor force participation, worse health and educational outcomes for children and transfer of violence to the next generation (Morrison and Orlando, 1999). Beyond imposing economic costs, domestic violence also impedes development by depriving women of such basic human rights as the right to life, liberty and security of person and the freedom from torture or cruel and inhuman or degrading treatment or punishment. ${ }^{[3]}$

There are various theories attempting to explain the reasons for intimate partner violence, differing in their focus, whether on the personal characteristics, the quality of the relationship, the neighborhood environment or the societal factors such as norms (Loue, 2001). This study derives its theoretical content mainly from the social learning theory of domestic violence which holds that people bring their childhood experiences to their adult intimate relationships by imitating what their parents had done in similar situations (Mihalic and Elliot 1997). Childhood observations of parents' interactions provide a model of how to behave in future relationships. Children who routinely witness physical abuse between their parents are likely to learn that hitting could be an acceptable behavior in response to stress and anger in the family. A boy observing his father's use of violence during marital conflicts might believe in the effectiveness of physical aggression to control the other in an intimate relationship. A girl in the same situation might accept being abused as an unavoidable part of the marriage life. Therefore, men and women who grew up witnessing violence between their parents are at greater risk of recreating abusive spou-

[1] The World Health Organization defined domestic violence as "any behavior within an intimate relationship that causes physical, psychological or sexual harm to those in the relationship." Such behavior includes acts of physical aggression, psychological abuse or sexual coercion. (Krug et al., 2002)

[2] Levinson (1989) found that domestic violence against women exists in 86 of the 90 societies under investigation. Nearly 50 studies around the world give estimates ranging from $10 \%$ to more than $60 \%$ for women's lifetime victimization (Watts and Zimmerman, 2002; Kishor and Johnson, 2004). Estimates differ widely from country to country, probably due to cultural differences, small sample sizes, sampling methods and wording of questions (Ellsberg et al., 2001). Studies using large samples in developed countries report lifetime victimization estimates between $20 \%$ and $30 \%$. Two studies conducted in Turkey with large sample sizes report consistently that one in every three women was attacked by her husband physically at least once. (T.C. Başbakanlık Aile Araştırma Kurumu Başkanlığı, 2000; Altınay and Arat, 2007). Studies also find that the majority of victims experience violence multiple times. The National Violence Against Women (NVAW) Survey conducted in the US revealed that $22 \%$ of the respondents were victims of physical domestic violence, $66 \%$ of whom were victimized more than once, and 20\% more than 10 times (Tjaden and Thoennes, 2000).

[3] The Universal Declaration of Human Rights, accessed on 20.01.2011 at http://www.un.org/en/documents/udhr/index.shtml 
sal relationships. Many studies have reported results supporting this "intergenerational transmission of violence" hypothesis for both the developed and the developing countries. Witnessing domestic violence is a risk marker for spouse abuse among both males and females (Hotaling and Sugarman, 1986), and men and women who had witnessed parents who hit each other were three times more likely to do so than those who had not abused their own partners (Straus, 1979). Panda and Agarwal (2005) report for India that men are three times more likely to be abusive and wives almost four times more likely to be abused if they had witnessed domestic violence as children.

Pollak (2004) makes an original contribution to the domestic violence literature by modeling the intergenerational transmission of violence hypothesis. Unlike most economic models of domestic violence which use the rational choice framework, he uses tools of the evolutionary game theory to study the mechanisms through which domestic violence passes from one generation to the next. Attention is directed to the marriage market as an important link for transmission of violence between generations, and it is suggested that any measures, such as divorce policies, which reduce domestic violence in the current period, will reduce it further in the future. The effect works out cumulatively over time as fewer and fewer children grow up in violent families. Pollak suggests that any violence prevention program's impact on domestic violence should be evaluated by its potential cumulative effect over generations.

This paper offers a reformulation of Pollak's model by incorporating the impact of education on domestic violence and the feedback relationship between the prevalence of violence in a society and men's likelihood to abuse their partners at home. The first extension is the impact of a high education level on domestic violence. One of the most consistent findings of empirical studies on domestic violence has been the protective effect of higher education (Vyas and Watts 2009). ${ }^{[4]}$ College-educated women are significantly less likely to experience domestic violence and more likely to leave their partners in case of violence. Moreover, college-educated men are less likely to resort to violence when confronted with marital problems. The other extension of Pollak's model is based on the idea that physical aggression becomes an acceptable method of conflict solution and relieving tension in cultures where violence is a continuous and pervasive part of life. Husbands become less hesitant to use violence and wife abuse becomes more prevalent in such societies (Levinson, 1989). Therefore, there is a two-way relationship between the level of violence in the community and the level of violence at home.

Before proceeding to the main concern of the paper we briefly summarize some of the theoretical work on domestic violence done by economists. Tauchen et al. (1991) investigate the relationship between income and domestic violence in a non-cooperative model. The husband is the dominant spouse and can use violence to coerce his wife to behave as he prefers or he may simply derive pleasure from inflicting pain. The wife decides on her level of obedience and both spouses choose the amount of transfer to be made to the other party. The marriage remains intact as long as the marriage util-

[4] We choose to focus only on college education because the amount of education on domestic violence decreases noticeably at lower levels. Even the effect of high school education is weak and inconsistent (Kishor and Johnson, 2004). 
ity of each spouse is not less than his or her utility outside the home. Income takes an important role and can work both ways, depending on who controls it: a husband can "buy" more violence by transferring some of his income to his wife when she is held at the minimum utility to stay in the marriage or she can "bribe" him to escape violence - therefore, more of her income helps reduce violence. They show that, as their share of family income increases, low income women are less abused.

Farmer and Tiefenthaler's (1997) non-cooperative model suggests, in line with the predictions of cooperative bargaining models, that employment, higher income, better support services, etc. decrease the level of violence in the relationship by making a wife less dependent on her husband.

Bloch and Rao (2002) and Farmer and Tiefenthaler (1996) build dynamic models where use of violence and escape from violence, respectively, function as signals to the other party. Bloch and Rao (2002) suggest an explanation to high marital conflict and wife abuse related to dowry disputes in India. A husband's satisfaction with the marriage is private information, thus, the wife and her family cannot observe it. Unhappy husbands demand income transfer from their wives' family for not divorcing. They can use violence as a signal to reveal their dissatisfaction. When a wife's family observes violence, they have to decide whether to make the transfer or not. According to Farmer and Tiefenthaler (1996), women in abusive marriages know their threat points or utility of out-of-marriage opportunities, but their husbands do not. An abused wife can leave home and stay at a shelter temporarily to signal her low tolerance for violence. Then the husband has to decide on the level of violence by considering the probability that she might not be bluffing. The model has an equilibrium with a lower level of violence where even women with high tolerance for violence benefit from using shelter services.

Bobonis et al. (2009) adapt Bloch and Rao's (2002) model to analyze the impact on domestic violence of a conditional cash transfer program in rural Mexico. Husbands unhappy with their gains from marriage try to extract income or obedience from their wives by threatening them with violence. Violence leads to inefficiency, as some of the marriage gains are lost in case of abuse. The researchers show the existence of an equilibrium where an increase in the wife's income decreases the level of physical abuse, even though the husband makes more threats. They report that women who received the conditional cash transfer experienced less violence than other women in comparable non-participating households.

Bowlus and Seitz (2006) build a dynamic model relating domestic violence, employment and divorce. The husband decides whether to abuse his wife in the current period by taking into account its effect on her probability of choosing employment and divorce in the next period. The wife decides whether to remain married by considering her husband's past behavior, and she makes employment decisions by taking into account his future abusive reactions to her working. The model suggests that abused wives seek employment and employed women are more likely to divorce abusive husbands. Their empirical work shows that severe domestic violence is the most important predictor of divorce, and a wife's employment reduces the risk of violence because working women are more likely to divorce abusive husbands. 
Aizer (2010) studies the relationship between labor market conditions and domestic violence in a cooperative bargaining model. She shows that an increase in a wife's relative wage increases her power in the marriage by decreasing her own utility loss in case of divorce. Both spouses' utility functions include consumption and violence, with violence increasing the husband's utility but decreasing the wife's utility. As the wife's out-of-marriage options improve, the husband has to decrease violence to keep her marriage utility at least as large as her outside utility. She finds that when labor market conditions for women improve, and so their wages increase relative to men's, severe domestic violence as measured by female hospitalizations for assault decreases - even for non-working women.

DeRiviere (2008) offers a critique of the economic approach to domestic violence in general and of using rational choice models in particular. She states that many of the bargaining formulations are not well-suited to study the complexity of domestic violence which is linked to many factors outside the economic realm. Policy conclusions derived from these narrow models could be ineffective or even damaging. Better models endogenizing key economic variables and including time-varying and path-dependent decision-making processes that evolve over time in response to the experience of abuse have to be built.

We proceed as follows. In section 2 we briefly overview Pollak's model. Section 3 extends Pollak's model by incorporating the impact of education on domestic violence. We form an assortative mating model which allows selective matching on the basis of education background, that is to say highly educated women marry highly educated men. In section 4 we form a feedback mechanism model in which the probability that a husband will be violent depends on the prevalence of domestic violence in the society. We assume that if domestic violence is widespread in the society, the probability that a husband will use violence is high. On the contrary, if the domestic violence rate is decreasing, then it would be less likely that a husband would inflict violence. Section 5 gives a numerical example to compare our findings with Pollak's model and finally section 6 concludes our presentation.

\section{Pollak (2004): A Dynamic Model of Domestic Violence}

Due to increasing worldwide interest in domestic violence, studies from various academic disciplines seeking explanations for the phenomenon began to accumulate in the 1990s. Robert Pollak's theoretical work on the evolution of domestic violence in a society is one such contribution coming from the field of economics.

Pollak (2004) tracks changes in the fraction of violent families, i.e. families in which domestic violence is observed, in the population over time by utilizing the intergenerational transmission of violence hypothesis. According to this hypothesis, children raised in a family environment where violence between parents is common internalize spousal abuse and carry it into their own relationships as adults. Studies find that in their intimate relationships, men are more likely to be abusive and women are less likely to resist violence if their family of origin had a history of domestic violence. (Altınay and Arat, 2007; 
Cubbins and Vannoy, 2005; Heyman and Slep, 2002; Martina et al., 2002; Page and İnce, 2008; Panda and Agarwal, 2005; Stith et al., 2000).

Two points have to be noted here. First, it is assumed that only men can be perpetrators of marital violence and all the victims are women. There is a growing literature showing that this view is incorrect at least in the cases of the United States and Canada, and that intimate partner abuse is usually mutual and the incidence of violence initiated by women is almost as high (Carney et al., 2007). Although there is an on-going debate about the comparability of violence committed by women to that committed by men in terms of its effects on the victim, it might be the case that men inflict more pain and create fear whereas women are more likely to engage in relatively minor acts of aggression (Anderson, 2010). This bi-directional pattern of violence is less likely to be observed in less developed countries with traditional values built on strict gender inequality (Garcia-Moreno et al., 2005). Nevertheless, the results of the model would not change in the presence of wife-initiated violence as long as the spousal abuse is mutual and the negative impact on children of witnessing parental violence is not significantly elevated in the bi-directional case.

Secondly, the observation that adults who were physically abused as children by their parents are also more likely to be involved in a violent intimate relationship (Murray and Kantor, 1994; Stith et al., 2000; Swinford et al., 2000; Ehrensaft, 2003) is not included in the model. The other related findings in this literature show three more points that have been omitted: abusive parenting by mothers being more strongly related to victimization of women (Simmons et al., 1993), parents with a history of child abuse being more likely to abuse their children (Lunkenheimer et al., 2006) and co-occurrence of interparental violence and child abuse heightening the risk of future domestic violence (Heyman and Slep, 2002) Therefore, the analysis in this paper does not touch upon the second mechanism, harsh physical punishment in childhood, by which domestic violence is carried over to the next generation. The model's shortcoming in this respect is lessened to some extent by the finding that there is a significant overlap between the cases of wife abuse and those of child physical abuse (Holt et al., 2008). Edleson (1999), reviewing 35 related studies, reports that the overlap ranges between 30-60\%. Chan (2011) finds for Hong Kong that spousal violence increases the risk of corporal punishment and physical maltreatment by 6 and 9 times, respectively.

Another assumption of the model is that men and women having similar family backgrounds in terms of domestic violence are more likely to marry each other. This has an effect on the probability of a match with a similar mate in the marriage market. Simons et al. (1993) find some indirect evidence for this type of assortative mating: children abused by their parents are at higher risk of aggressive/deviant behavior; as adults they tend to associate with similar individuals, and men exhibiting deviant behavior are more likely to abuse their wives. ${ }^{[5]}$

[5] Admittedly, this finding supports the assumption only for the cases where spousal violence and child abuse exist together. Even though the assumption sounds intuitive, we failed to find sufficient supporting evidence. There seems to be support for assortative mating based on antisocial behavior in general (Dutton, 2006: 141). Pollak (2004) is also silent 
Agents live for two periods, first as a child, then as an adult. A child witnesses domestic violence or not in his or her family. The child grows to be an adult who marries and has children. Later in the adulthood, a husband might abuse his wife or not; a wife might stay or leave (divorce) if violence occurs. ${ }^{[6]}$ The model uses the match probability, the probability that a husband type becomes violent and the probability that a wife type chooses to divorce in case of violence to calculate the domestic violence rate in a particular generation. The fraction of violent families in a society in period $t+1\left(\pi_{t+1}\right)$ depends on the following probabilities (Pollak, 2004):

- the fraction of men and women in the marriage market at $t+1$, who grew up in violent homes at $\mathrm{t}$ or the fraction of violent families at $\mathrm{t}\left(\boldsymbol{\pi}_{t}\right)$

- the probability that a man grown up in a violent home will be violent in his own marriage $\left(p_{v}\right)$

- the probability that a man grown up in a non-violent home will be violent in his own marriage $\left(p_{\bar{v}}\right)$

- the probability that a woman grown up in a violent home will stay married to an abusive man $\left(S_{v}\right)$

- the probability that a woman grown up in a non-violent home will stay married to an abusive man $\left(S_{\bar{v}}\right)$

- the probability that men and women with a similar family background will marry each other $(\sigma)$.

Pollak assumes that:

- in their own marriage, men who grew up in a violent family environment are more likely to abuse their wives than men who grew up in non-violent families $\left(p_{v}>p_{\bar{v}}\right)$.

- a woman who grew up in a violent family is less likely to divorce an abusive husband than a woman grown up in a non-violent family $\left(s_{v}>s_{\bar{v}}\right)$.

- men and women who share a similar family history in terms of violence are more likely to marry each other $(\sigma>0)$.

The structure of the marriage market determines the likelihood of matches between men and women with similar or different family backgrounds. Pollak assumes that there are three marriage submarkets: the market where men and women coming from violent families meet, the market where men and women coming from non-violent families meet and the mixed market where men and women with different family backgrounds meet. $\sigma \pi_{t}$ of adults ready for marriage at $t+1$ enter the first submarket. $\pi_{t}$ of men and women had witnessed domestic violence in their childhood; $\sigma$ of them will meet a mate

on this issue. As will be seen in the numerical example, this assumption has a surprisingly minor effect on the results. We want to thank the anonymous referee who raised the point.

[6] This assumes that a woman can get a divorce in a short period after her husband becomes violent, and that their children are not exposed to domestic violence long enough to increase their future risk simplifies the model. Therefore, $\pi$ can be thought of as the proportion of families in which domestic violence occurs consistently over a long term. Moreover, divorce in this model occurs only as a result of physical aggression by a husband. 
having a similar family history. Likewise, $\sigma\left(1-\pi_{t}\right)$ of marriage candidates enter the second submarket. The rest, $(1-\sigma) \pi_{t}+(1-\sigma)\left(1-\pi_{t}\right)$ will be in the third submarket.

Depending on the behavioral probabilities $\left(p_{v}, p_{\bar{v}}, s_{v}, s_{\bar{v}}\right)$, the structure of the marriage market $(\sigma)^{[7]}$ and an initial value of the rate of domestic violence in the society, the model predicts the rate of change in domestic violence over the generations and the equilibrium rate of violence, where there would not be any long-term change in violence as long as the parameter values remain constant. Therefore, the model suggests the potential effects on domestic violence over generations of an intervention in the current period, such as enacting laws against wife abuse.

\section{The Effect of Higher Education on the Intergenerational Transfer of Domestic Violence}

In this section, Pollak's model will be extended by incorporating the effects of higher education on the dynamics of domestic violence. This is a straightforward extension because only the underlying behavioral probabilities and the structure of the marriage market change. This section also serves to elaborate the workings of Pollak's model.

Higher education is found to protect women from domestic violence, whether it is the husband or the wife who is the college graduate (Vyas and Watts, 2009). Collegeeducated women are at considerably lower risk of abuse by their husbands. Altinay and Arat (2007) report for Turkey that while one-third of all women are victims of wife abuse, only $12 \%$ of college-educated women experience domestic violence. Women who are college graduates are also more likely to divorce if violence occurs (KingstonRiechers, 2001).

One reason for the protective effect of women's higher education is the economic power such an education puts within reach. A significant majority of college-educated women join the labor market and these women have better paying jobs compared to less educated women (Tansel, 1999). Economic power held by a woman strengthens her bargaining power within marriage by increasing her outside options; a husband would be more hesitant to use violence against his wife if she can make a credible threat of leaving (Koç and Erkin, 2011).

Empirical studies also find that higher education still protects women even when its effect on economic power is controlled. A married Indian woman with 10 years of education is almost 4 times more likely to suffer from domestic violence compared to women with higher education even after significant related variables such as husband's education, employment and living standards are controlled (Ackerson et al., 2008). College life might increase young women's self-confidence as it usually provides the first experience of independent living in their lives. Moreover, higher education and college environment, by emphasizing values like open-mindedness, tolerance, communication and cooperation, might lead students to adopt an egalitarian stance with respect to rela-

[7] In this setup where potential mates are not differentiated by their level of education, the match probability contains all the information to predict marriage outcomes. In the next section, we have to know the fraction of college graduates as well. 
tions between the sexes. Therefore, not only are college-educated women less likely to accept violence, but also college-graduate men are more likely to stay away from violence (Blair-Johnson and Boria-Das, 2009; Cubbins and Vannoy, 2005). The probability that a man will act abusively toward his wife is twice as high in the general population as it is among college graduates in Turkey (Altınay and Arat, 2007). Ackerson et al. (2008) report similar findings for India.

We assume that college-educated men are less likely to be violent at home and that college-educated women are more likely to divorce a violent husband. Let the probability that a college-graduate man will abuse his wife be $\alpha p_{v}$ or $\alpha p_{\bar{v}}$, whether he grew up in a violent or non-violent family. Let also the probability that a college-graduate woman will stay with a violent husband be $\beta s_{v}$ or $\beta s_{\bar{v}}$, whether she grew up in a violent or non-violent family, where both $\alpha$ and $\beta$ are positive and less than 1 .

Another assumption of the model is that the college attendance rates for people coming from families with a history of domestic violence and people coming from non-violent families are the same. This makes the model less cumbersome but at the expense of being less realistic. It is very likely that these two groups of people attend higher education at different rates. There is considerable evidence that children abused and exposed to violence in their family are at higher risk of delayed cognitive development and poor academic functioning; they perform lower on standardized tests; they have higher absenteeism and are more likely drop out before completing high school (Wodorski et al., 1990; Kurtz et al., 1993; Leiter and Johnsen, 1997; Margolin and Gordis, 2000). However, as Note 11 explains, this omission will not have any noticeable impact on the results because the single attendance rate might be considered as an average of the rates for the two groups.

Here we will assume that there are equal numbers of men and women who are college graduates, and that they marry each other. Both assumptions are supported for many middle to high income countries. Empirical studies document the high proportion of marriages between educational-equals (especially for college graduates) and the sex ratio in the higher education is close to one in the west (Schwartz and Mare 2005). Women in middle income countries have been attending college in larger numbers. For example, almost half of the college graduates have been women in Turkey since the 1990s. ${ }^{[8]}$

The number of marriage submarkets in the model increases to six with the introduction of higher education. The three submarkets in Pollak's model exist separately for college graduates and for other adults with less education. Let the proportion of college graduate men and women among the adults ready for marriage be $e$. Then, the probability that a woman coming from a violent family will marry a man who has also a violent family history is $e \pi_{t}\left(\sigma+(1-\sigma) \pi_{t}\right)$ for college graduates, and $(1-e) \pi_{t}\left(\sigma+(1-\sigma) \pi_{t}\right)$ for others. The former probability is calculated as follows: at $t+1$, the ratio of women who both have college education and come from violent families is $e \pi_{t} . \sigma$ of these women will be in the submarket where only college graduates with violent family histories enter. Therefore, they all will marry men with a similar background. The rest, $(1-\sigma)$,

${ }^{[8]}$ Türkiye İstatistik Kurumu, accessed on 28.10.2010 at http://www.turkstat.gov.tr. 
will be in the mixed submarket for college graduates. The ratio of men with a violent family history in this market and thus the probability of marrying one of them is $\pi_{t}$. The latter probability is derived in the same way for women without a college education.

The only way for a woman coming from a violent family to meet man with a nonviolent background is to enter the relevant mixed submarket. $(1-\sigma) \pi_{t}$ of women and $\left(1-\pi_{t}\right)$ of men in the two mixed submarkets will be such men and women. Therefore, the probability of meeting a man with no history of violence for a woman coming from a violent family is $e(1-\sigma) \pi_{t}\left(1-\pi_{t}\right)$ or $(1-e)(1-\sigma) \pi_{t}\left(1-\pi_{t}\right)$, whether she is a college graduate or not.

Likewise, the probability of a woman with no history of violence to marry a man coming from a violent family is $e(1-\sigma) \pi_{t}\left(1-\pi_{t}\right)$ or $(1-e)(1-\sigma) \pi_{t}\left(1-\pi_{t}\right)$, and her probability of marrying a man coming from a non-violent family is $e\left(1-\pi_{t}\right)\left(\sigma+(1-\sigma)\left(1-\pi_{t}\right)\right)$ or $(1-e)\left(1-\pi_{t}\right)\left(\sigma+(1-\sigma)\left(1-\pi_{t}\right)\right)$, depending on her education.

Violence transmitted to the next generation will depend today at period $t$ on the violence by men who are coming from violent families and are college-educated $\sigma e \pi_{t} \alpha p_{v} \beta s_{v}+(1-\sigma)\left(e \pi_{t}^{2} \alpha p_{v} \beta s_{v}+e \pi_{t}\left(1-\pi_{t}\right) \alpha p_{v} \beta s_{\bar{v}}\right)$ [9]; the violence by men who are coming from non-violent families and are college-educated is $\sigma e\left(1-\pi_{t}\right) \alpha p_{\bar{v}} \beta s_{\bar{v}}+(1-\sigma)\left(e \pi_{t}\left(1-\pi_{t}\right) \alpha p_{\bar{v}} \beta s_{v}+e\left(1-\pi_{t}\right)^{2} \alpha p_{\bar{v}} \beta s_{\bar{v}}\right)$, the violence by men who are coming from violent families and are not college-educated is $\left.\sigma(1-e) \pi_{t} p_{v} s_{v}+(1-\sigma)\left((1-e) \pi_{t}^{2} p_{v} s_{v}+(1-e) \pi_{t}\left(1-\pi_{t}\right) p_{v} s_{\bar{v}}\right)\right)$, and the violence by men who are coming from non-violent families and are not college-educated is $\sigma(1-e)\left(1-\pi_{t}\right) p_{\bar{v}} s_{\bar{v}}+(1-\sigma)\left((1-e) \pi_{t}\left(1-\pi_{t}\right) p_{\bar{v}} s_{v}+(1-e)\left(1-\pi_{t}\right)^{2} p_{\bar{v}} s_{\bar{v}}\right)$.

The fraction of violent families at $t+1\left(\pi_{t+1}\right)$ is the sum of the terms above and is given by the following equation:

$$
\pi_{t+1}=\left[\begin{array}{l}
\sigma e \pi_{t} \alpha p_{v} \beta s_{v}+(1-\sigma)\left(e \pi_{t}^{2} \alpha p_{v} \beta s_{v}+e \pi_{t}\left(1-\pi_{t}\right) \alpha p_{v} \beta s_{\bar{v}}\right)+ \\
\sigma e\left(1-\pi_{t}\right) \alpha p_{\bar{v}} \beta s_{\bar{v}}+(1-\sigma)\left(e \pi_{t}\left(1-\pi_{t}\right) \alpha p_{\bar{v}} \beta s_{v}+e\left(1-\pi_{t}\right)^{2} \alpha p_{\bar{v}} \beta s_{\bar{v}}\right)+ \\
\left.\sigma(1-e) \pi_{t} p_{v} s_{v}+(1-\sigma)\left((1-e) \pi_{t}^{2} p_{v} s_{v}+(1-e) \pi_{t}\left(1-\pi_{t}\right) p_{v} s_{\bar{v}}\right)\right)+ \\
\sigma(1-e)\left(1-\pi_{t}\right) p_{\bar{v}} s_{\bar{v}}+(1-\sigma)\left((1-e) \pi_{t}\left(1-\pi_{t}\right) p_{\bar{v}} s_{v}+(1-e)\left(1-\pi_{t}\right)^{2} p_{\bar{v}} s_{\bar{v}}\right)
\end{array}\right]
$$

The model reaches an equilibrium when the change in the ratio of violence stops, $\left(\pi_{t+1}-\pi_{t}=0\right)$, and thus domestic violence stays constant between the current and the next generation, $\left(\pi_{t}=\pi_{t+1}\right)$. Ignoring the time subscript at equilibrium, (1) can be written as:

${ }^{[9]}$ Of these men, $\left(\sigma \pi_{t}+(1-\sigma) \pi_{t}^{2}\right)$ marry women having similar family backgrounds and the rest $\left((1-\sigma) \pi_{t}\left(1-\pi_{t}\right)\right)$ marry women coming from non-violent families. Violence occurs in $\alpha p_{\nu}$ of these marriages. In violent marriages, $\beta s_{\nu}$ of the women coming from violent families and $\beta s_{\bar{v}}$ of the latter choose to stay. In those marriages, children are exposed to violence long enough that it has an impact on their adult behavior. 


$$
\begin{aligned}
& \pi=\sigma e \pi \alpha p_{v} \beta s_{v}+(1-\sigma)\left(e \pi^{2} \alpha p_{v} \beta s_{v}+e \pi(1-\pi) \alpha p_{v} \beta s_{\bar{v}}\right)+ \\
& \sigma e(1-\pi) \alpha p_{\bar{v}} \beta s_{\bar{v}}+(1-\sigma)\left(e \pi(1-\pi) \alpha p_{\bar{v}} \beta s_{v}+e(1-\pi)^{2} \alpha p_{\bar{v}} \beta s_{\bar{v}}\right)+ \\
& \left.\sigma(1-e) \pi p_{v} s_{v}+(1-\sigma)\left((1-e) \pi^{2} p_{v} s_{v}+(1-e) \pi(1-\pi) p_{v} s_{\bar{v}}\right)\right)+ \\
& \sigma(1-e)(1-\pi) p_{\bar{v}} s_{\bar{v}}+(1-\sigma)\left((1-e) \pi(1-\pi) p_{\bar{v}} s_{v}+(1-e)(1-\pi)^{2} p_{\bar{v}} s_{\bar{v}}\right)
\end{aligned}
$$

Writing (2) as a quadratic equation of $\pi$ leads us to find the equilibrium value of $\pi$ and to show that it is unique:

$$
\begin{aligned}
& G(\pi)=\left[(1-e(1-\alpha \beta))(1-\sigma)\left(p_{v} s_{v}-p_{v} s_{\bar{v}}-p_{\bar{v}} s_{v}+p_{\bar{v}} s_{\bar{v}}\right)\right] \pi^{2}+ \\
& {\left[(1-e(1-\alpha \beta))\left(\sigma p_{v} s_{v}+(1-\sigma) p_{v} s_{\bar{v}}+(1-\sigma) p_{\bar{v}} s_{v}-(2-\sigma) p_{\bar{v}} s_{\bar{v}}\right)-1\right] \pi+(1-e(1-\alpha \beta)) p_{\bar{v}} s_{\bar{v}}=0}
\end{aligned}
$$

This function, expressed as $G(\pi)=\pi_{t+1}-\pi_{t}$, can also be seen as the difference of the violence ratio between two consecutive generations. Therefore, the solution for the equality $G(\pi)=0$ gives the equilibrium value for $\pi$. Let $\theta=1-e(1-\alpha \beta)$,

$$
\begin{aligned}
& A_{1}=\theta(1-\sigma)\left(p_{v} s_{v}-p_{v} s_{\bar{v}}-p_{\bar{v}} s_{v}+p_{\bar{v}} s_{\bar{v}}\right) \\
& A_{2}=\left(\theta\left(\sigma p_{v} s_{v}+(1-\sigma) p_{v} s_{\bar{v}}+(1-\sigma) p_{\bar{v}} s_{v}-(2-\sigma) p_{\bar{v}} s_{\bar{v}}\right)-1\right),
\end{aligned}
$$

and $A_{3}=\theta p_{\bar{v}} s_{\bar{v}}$. Then $G(\pi)$ can be written as $G(\pi)=A_{1} \pi^{2}+A_{2} \pi+A_{3}$.

The existence and the uniqueness of the equilibrium can be shown as follows: $A_{1}$ can be rewritten as $\theta(1-\sigma)\left(p_{v}-p_{\bar{v}}\right)\left(s_{v}-s_{\bar{v}}\right)$, which is positive because $p_{v}>p_{\bar{v}}, s_{v}>s_{\bar{v}}, 1>\sigma, \theta>0 . \pi$ takes values between 0 and $1 . G(0)=A_{3}=\theta p_{\bar{v}} s_{\bar{v}}>0$ and $G(1)=A_{1}+A_{2}+A_{3}=\theta p_{v} s_{v}-1<0$. Since $G(\pi)$ is a quadratic function, it is continuous and twice differentiable at every point in $[0,1]$. Its second derivative $2 A_{1}$ is always positive, so it is strictly convex and its graph crosses the $\pi$ axis only once in [0,1]. Therefore, there is a single $\pi$ value that satisfies the equilibrium condition $G(\pi)=0$. The proof is shown graphically in Figure 1.

Figure 1

\section{Showing the Uniqueness of the Equilibrium}

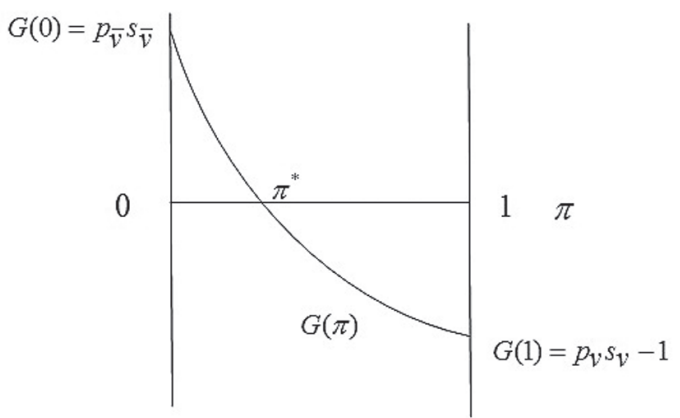


It is easy to show that the equilibrium violence level in this model is a fraction of the violence rate in Pollak's by rearranging (2):

$$
\pi=[1-e(1-\alpha \beta)] \pi_{P K}=\theta \pi_{P K}
$$

where

$$
\pi_{P K}=\left[\begin{array}{l}
\sigma \pi p_{v} s_{v}+(1-\sigma)\left(\pi^{2} p_{v} s_{v}+\pi(1-\pi) p_{v} s_{\bar{v}}\right)+\sigma(1-\pi) p_{\bar{v}} s_{\bar{v}} \\
+(1-\sigma)\left(\pi(1-\pi) p_{\bar{v}} s_{v}+(1-\pi)^{2} p_{\bar{v}} s_{\bar{v}}\right)
\end{array}\right]
$$

is the equilibrium level of violence in Pollak's model. Including education in the model decreases the level of violence since $(1-e(1-\alpha \beta)<1)$ : the higher the ratio of college graduates in the population, the less is the fraction of violent families. The impact of education also depends on how different college-educated men and women behave with respect to domestic violence: the more differently they behave (smaller values for $\alpha$ and $\beta$ ), the less is the level of violence.

The equilibrium level of violence increases with an increase in any of the parameters $\left(\sigma, p_{v}, s_{v}, p_{\bar{v}}, s_{\bar{v}}, \alpha, \beta\right)$ and decreases as the proportion of college graduates $(e)$ rises in the population. The decreasing effect on $\pi$ of a change in $e$ will be proven here; another parameter's effect on violence can be shown similarly.

We can write $G(\pi, e)=0$ by using the implicit function theorem. Taking the derivative gives $(\partial G / \partial \pi) d \pi+(\partial G / \partial e) d e=0$ and thus

$$
\frac{d \pi}{d e}=-\frac{\partial G / \partial e}{\partial G / \partial \pi}
$$

From the proof of the uniqueness of the equilibrium value, we know that $(\partial G / \partial \pi)<0$ at $\pi$. Then, $(d \pi / d e)$ and $(\partial G / \partial e)$ must have the same sign. Taking the partial derivative of $G(\pi, e)=0$ with respect to $e$ gives

$$
\frac{\partial G}{\partial e}=-(1-\alpha \beta)\left[\begin{array}{l}
(1-\sigma)\left(p_{v}-p_{\bar{v}}\right)\left(s_{v}-s_{\bar{v}}\right) \pi^{2}+ \\
\left(\left(\sigma p_{v}+(1-\sigma) p_{\bar{v}}\right)\left(s_{v}-s_{\bar{v}}\right)+s_{\bar{v}}\left(p_{v}-p_{\bar{v}}\right)\right) \pi+p_{\bar{v}} s_{\bar{v}}
\end{array}\right]
$$

$(1-\alpha \beta)$ and all the terms in the bracket are greater than zero. Therefore, $d \pi / d e<0$, which means that the higher the ratio of college graduates the lower the rate of domestic violence.

\section{The Relationship Between Domestic Violence in the Society and Men's Proclivity to Violence at Home}

Secondly, the assumption that a husband's probability of being abusive is related to the prevalence of domestic violence in the society will be included in the model. Wolfgang and Ferracuti (1967) argue that some subcultures in a society might develop 
cultural norms that justify the use of violence to uphold values significant for the group. Physical aggression will be more pervasive in such groups compared to the rest of the society. One arena where use of force is observed frequently is the family. Levinson and Malone (1980) generalize this observation to societies: domestic violence is considerably higher in violent societies than in peaceful ones. Such societies usually have norms legitimizing a woman's physical punishment by her husband in order to sustain a strict gender hierarchy. According to the ecological approach to domestic violence, violence in the community and such norms in the society have an increasing effect on wife abuse (Krug et al., 2002). We assume that the domestic violence rate in the society is closely related to the strength of such norms: when they are prevalent, wife abuse will be common; a husband, observing domestic violence around him and securing the legitimacy provided by the norms, will restrain himself less in using violence in a marital conflict. On the other hand, as fewer husbands engage in abusive acts and the domestic violence rate begins to fall, the norms will weaken, and thus have a lesser effect on individual behavior over time.

Therefore, we will assume that a man's probable use of violence at home increases as domestic violence becomes more widespread in the society. Let the probability of being violent at $t+l$ for a man who is coming from a violent family be $p_{v}^{t+1}=p+m \pi_{t}$. $p$ might reflect the effects of family background, genetic factors, and other personal characteristics on committing violence. Then, $m \pi_{t}$ would show the effect of the prevalence of violence in the society; $m$ is a measure of this type man's responsiveness to the violence around him. Let the probability of a man with no history of violence to be abusive in his own marriage at $t+1$ be $p_{\bar{v}}^{t+1}=\bar{p}+n \pi_{t} \cdot(1>p>\bar{p}>0)$ ve $(1>m>n>0)$.

The fraction of violent families at the equilibrium can be written as in (2), except that $p_{v}$ is replaced with $(p+m \pi)$ and $p_{\bar{v}}$ with $(\bar{p}+n \pi)$ :

$$
\begin{aligned}
& \pi=\sigma e \pi \alpha(p+m \pi) \beta s_{v}+(1-\sigma)\left(e \pi^{2} \alpha(p+m \pi) \beta s_{v}+e \pi(1-\pi) \alpha(p+m \pi) \beta s_{\bar{v}}\right)+ \\
& \sigma e(1-\pi) \alpha(\bar{p}+n \pi) \beta s_{\bar{v}}+(1-\sigma)\left(e \pi(1-\pi) \alpha(\bar{p}+n \pi) \beta s_{v}+e(1-\pi)^{2} \alpha(\bar{p}+n \pi) \beta s_{\bar{v}}\right)+ \\
& \left.\sigma(1-e) \pi(p+m \pi) s_{v}+(1-\sigma)\left((1-e) \pi^{2}(p+m \pi) s_{v}+(1-e) \pi(1-\pi)(p+m \pi) s_{\bar{v}}\right)\right)+ \\
& \sigma(1-e)(1-\pi)(\bar{p}+n \pi) s_{\bar{v}}+(1-\sigma)\left((1-e) \pi(1-\pi)(\bar{p}+n \pi) s_{v}+(1-e)(1-\pi)^{2}(\bar{p}+n \pi) s_{\bar{v}}\right)
\end{aligned}
$$

$G(\pi)$, used to find the equilibrium value and to show that it is unique, is now a cubic function:

$$
\begin{aligned}
& G(\pi)=\theta(1-\sigma)(m-n)\left(s_{v}-s_{\bar{v}}\right) \pi^{3}+\theta\left[\sigma\left(m s_{v}-n s_{\bar{v}}\right)+(1-\sigma)\left(\left(s_{v}-s_{\bar{v}}\right)(m-n)+s_{\bar{v}}(n+p-\bar{p})\right)\right] \pi^{2} \\
& +\left[\theta\left(s_{\bar{v}}(n+p-\bar{p})+\left(s_{v}-s_{\bar{v}}\right)(\sigma p+(1-\sigma) \bar{p})-1\right] \pi+\theta s_{\bar{v}} \bar{p}=0\right.
\end{aligned}
$$

Let $B_{1}$ and $B_{2}$ be respectively, $\theta(1-\sigma)(m-n)\left(s_{v}-s_{\bar{v}}\right)$ and $\left.\theta\left[\sigma\left(m s_{v}-n s_{\bar{v}}\right)+(1-\sigma)\left(s_{v}-s_{\bar{v}}\right)(n+p-\bar{p})+(1-\sigma)(m-n) s_{\bar{v}}\right)\right]$. Let $B_{3}=\left[\theta\left(s_{\bar{v}}(n+p-\bar{p})+\left(s_{v}-s_{\bar{v}}\right)(\sigma p+(1-\sigma) \bar{p})-1\right]\right.$ and $B_{4}=\theta s_{\bar{v}} \bar{p}$. Then $G(\pi)=B_{1} \pi^{3}+B_{2} \pi^{2}+B_{3} \pi+B_{4}$. 
The uniqueness of the equilibrium value can be shown similarly as in the previous section. $B_{1}$ and $B_{2}$ are positive: $\left(m>n, p>\bar{p}, s_{v}>s_{\bar{v}}, \theta>0, \sigma>0\right) . G(\pi)$ is continuous and twice differentiable in $[0,1]$. The second derivative of $G(\pi),\left(6 B_{1} \pi+2 B_{2}\right)$, and $B_{1}$ are positive; $G(0)=B_{4}=\theta s_{\bar{v}} \bar{p}$ is always positive and $G(1)=B_{1}+B_{2}+B_{3}+B_{4}=\theta(m+p) s_{v}-1$ is negative for realistic parameter values. Therefore, the graph of the function is concave upwards and it crosses the $\pi$ axis only once in the $[0,1]$ interval. Then, there must be a single $\pi$ value which satisfies $G(\pi)=0$.

We can also show that the equilibrium rate of domestic violence in this model with the feedback effect is lower compared to the model in the previous section, the education model. Let the violence rate in the education and the feedback effect models be respectively, $\pi$ and $\bar{\pi}$. We would observe initial values for the rate of violence in the society, the probability of being violent for a man with a violent family history and the probability of being violent for a man with a non-violent family history at $t=0$; let these values be equal in the two models $\left(\pi_{0}=\bar{\pi}_{0}, p_{v}=p+m \bar{\pi}_{0}, p_{\bar{v}}=\bar{p}+n \bar{\pi}_{0}\right)$. Let us also assume that the initial value for the rate of domestic violence is greater than the equilibrium values $\left(\pi_{0}>\pi, \bar{\pi}_{0}>\bar{\pi}\right) \cdot{ }^{[10]}$ As we start the dynamics of the education model and it reaches $t=1$, the rate of violence decreases $\left(\pi_{0}>\pi_{1}\right)$ because the difference equation $G(\pi)$ is negative as long as $\left(\pi_{t}>\pi\right)$. The feedback effect model also reaches the same rate at $t=1$ $\left(\bar{\pi}_{0}>\bar{\pi}_{1}=\pi_{1}\right)$ since the initial values of men's violence proneness are equal. In the next period, however, $\bar{\pi}_{2}$ becomes smaller than $\pi_{2}$ because the probabilities of men being violent decreases in the feedback effect model $\left(p_{v}>p+m \bar{\pi}_{1}\right.$ and $\left.p_{\bar{v}}>\bar{p}+n \bar{\pi}_{1}\right)$ while the probabilities in the education model, $p_{v}$ and $p_{\bar{v}}$, stay constant. Over generations, the difference between $\left(p_{v}-\left(p+m \bar{\pi}_{t}\right)\right)$ and $\left(p_{\bar{v}}-\left(\bar{p}+n \bar{\pi}_{t}\right)\right)$ grows, and when the feedback effect model reaches equilibrium at $t=T$, we have $\left(p_{v}>\left(p+m \bar{\pi}_{T}\right)\right)$ and $\left(p_{\bar{v}}>\left(\bar{p}+n \bar{\pi}_{T}\right)\right)$ . Since $\left(\partial \pi / \partial p_{v}\right)$ and $\left(\partial \pi / \partial p_{\bar{v}}\right)$ are positive, the equilibrium rate of domestic violence in the education model will be higher than that of the feedback effect model $(\pi>\bar{\pi})$.

If there is a feedback relationship between the prevalence of domestic violence in the society and men's likelihood of using violence at home, measures against wife abuse will be more successful because any fall in the rate of domestic violence will trigger a multiplier effect. Well implemented measures reduce the rate of violence, which causes men to be less willing to resort to violence. This leads to another fall in the rate of violence and the cycle goes on until the effect dies out.

For the feedback effect to work, a man has to perceive or be convinced that domestic violence is becoming less widespread in his community or in the society. That is why strong and multifaceted measures introduced with much publicity might be more likely to create the desired impact. Studies show that enacting change at the local and national levels is most likely as a result of coordinated community responses to domestic violence (Burton et al, 2000). Such a response would include contributions from the criminal justice, social service and health care systems as well as the media institutions. Public awareness campaigns against domestic violence can weaken the link between the violence in the community and the violence between couples (by decreasing $m$ and

${ }^{[10]}$ Assuming otherwise, i.e. $\left(\pi_{0}<\pi, \bar{\pi}_{0}<\bar{\pi}\right)$ would not change the result $(\pi>\bar{\pi})$. 
$n$ in the model). Enacting and implementing laws that help punish perpetrators and protect and support abuse victims might weaken the norms legitimizing a husband's use of violence at home. Such measures could lead to a substantial fall in the domestic violence rate in one generation, about 25-30 years, which is a relatively short time for major social changes to take place. In fact, the model predicts that most of the fall in the rate of domestic violence will occur in one generation as will be shown below.

\section{Comparing the Three Models with a Numerical Example}

Figure 2 shows that both extensions made to Pollak's model decrease the equilibrium rate of domestic violence. Each $G(\pi)$ function takes its highest value at $\pi=0$ and its lowest value at $\pi=1$. The uppermost graph $\left(G_{P}\right)$ derived from Pollak's model crosses the $\pi$ axis at $\pi_{P}^{*}$. $G_{P}$ will be negative for any $\pi$ above this equilibrium value, and thus, the domestic violence rate will fall towards $\pi_{P}^{*}$ over time. If $\pi$ is less than the equilibrium rate, $G_{P}$ will be positive and the domestic violence rate will keep increasing until it reaches $\pi_{P}^{*}$. $G_{E}$ is the graph of the education model. It reaches the equilibrium at a lower violence rate ( $\pi_{E}^{*}$ ). Adding the hypothesis of the dependence of men's probability of being abusive on the prevalence of domestic violence reduces the equilibrium rate down to $\pi_{F}^{*}$.

Figure 2

The $G(\pi)$ Functions and the Equilibrium Points for the Three Models

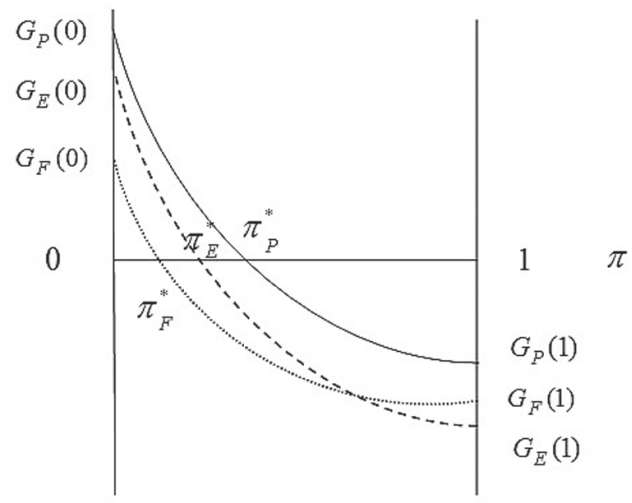

The differences between the models in terms of equilibrium value can be shown better with a numerical example. The initial rate of domestic violence $\left(\pi_{0}\right)$ is chosen as 0.35 , close to the figures reported for Turkey. Similarly, the proportion of college graduates is chosen as 0.15 . A college graduate's probability of abusing his wife is set to about one third of that of a man with lower education $(\alpha=0.3)$. This can be considered as a rough estimate based on Altınay and Arat's finding that one third of all women and one eighth of college-educated women experience domestic violence in Turkey. The 
probability of a college graduate woman to stay married in case of violence is assumed to be half of that of a less educated woman $(\beta=0.5)$.

A man with no history of violence in his original family is assumed to be violent in his marriage with probability $\left(p_{\bar{v}}\right) 0.25$ while the same probability for a man with a violent family background $\left(p_{v}\right)$ is set at 0.6 . These probabilities are calculated as follows: we set the initial rate of domestic violence at 0.35 , and thus, the proportion of non-violent families at $t=0$ has to be 0.65 . We also take into account that a man coming from a violent family is 2-3 times more likely to abuse his wife than a man who grew up in a non-violent family according to various studies. Finally, the probabilities have to be linked to the initial violence rate roughly with the equation $0.35 p_{v}+0.65 p_{\bar{v}}=0.35$.

It is assumed that the probability of staying married when faced with abuse will be 0.8 for a woman with a violent family background $\left(s_{v}\right)$ and 0.6 for a woman coming from a non-violent family $\left(s_{\bar{v}}\right)$. As explained in note 5 , divorce here means a quick separation of the couple as soon as the husband becomes abusive so that children are protected from witnessing violence. A woman who eventually ends an abusive relationship after suffering over the years is considered in the model to have stayed. Therefore, the number of actual divorces (caused by wife abuse) has to be higher than this model assumes. The match probability for a man and a woman with similar family backgrounds $(\sigma)$ is chosen as 0.67 .

For the feedback effect model, the parameter values for men's probability of being violent are chosen so that the initial probabilities at $t=0$ are equal. Therefore, the base probability of being violent for a man coming from a violent family $(p)$ is assumed to be 0.4 , and then his degree of being influenced by the violence around him $(m)$ is 0.5 so that $p_{v}^{t=0}=0.4+0.5 \times 0.35 \approx 0.60$. The values for the same parameters for a man with no history of violence, $\bar{p}$ and $n$, are 0.15 and 0.25 , respectively.

The results for the simulation carried out with these parameter values can be seen in Table 1 . All three models come very close to reaching equilibrium at the fourth generation. The rate of violence drops from $35 \%$ to between $12 \%$ and $21.8 \%$ in a century depending on the model. Assortative mating based on education and behavioral changes caused by higher education account for an almost $4 \%$ decrease in the equilibrium violence rate if we take Pollak's model as the base case. Adding different college attendance rates, one for people coming from families with no history of violence and a lower one for people who grew up in violent families, into the model would not change this result. ${ }^{[11]}$ The feedback effect accounts for another $6 \%$ drop, bringing the combined effect up to $10 \%$. The feedback effect model which also includes the education effect predicts the equilibrium rate to be $12 \%$, considerably lower than $21.8 \%$ of Pollak's model. As to the timing of the fall in the rate of domestic violence, half to two-thirds of the decrease will occur in the first generation; as the second generation gives way to the third, most of the change (more than $80 \%$ ) will have been realized.

\footnotetext{
[11] Assuming that the attendance rate for people coming from non-violent families is twice that of the other group and the average attendance rate is still $0.15 \%$, the equilibrium rate for the education model rises by only $0.1 \%$, hence it remains practically unchanged at $18 \%$.
} 
Table 1

The Results of the Simulation

\begin{tabular}{c|c|c|c}
\hline & Pollak Model & Education Model & Feedback Effect Model \\
\hline$\pi_{0}$ & 35.0 & 35.0 & 35.0 \\
\hline$\pi_{1}$ & 26.0 & 22.8 & 22.8 \\
\hline$\pi_{2}$ & 23.1 & 19.4 & 16.3 \\
\hline$\pi_{3}$ & 22.2 & 18.4 & 13.6 \\
\hline$\pi_{4}$ & 21.9 & 18.1 & 12.6 \\
\hline$\ldots$ & $\ldots$ & $\ldots$. & $\ldots$ \\
\hline$\pi^{*}$ & 21.8 & 18.0 & 12.0 \\
\hline
\end{tabular}

Changes in the values of violence probabilities have the biggest impact on the rate of domestic violence, followed by divorce probabilities. If the probabilities of wife abuse, $p_{v}$ and $p_{\bar{v}}$, decrease to 0.5 and 0.15 , respectively, the rate of violence drops to $10.5 \%$ in the education model and to $6.2 \%$ in the feedback effect model. Similarly, a $10 \%$ increase in the number of women divorcing their abusive husbands $\left(s_{v}\right.$ falls from 0.8 to $0.7, s_{\bar{v}}$ from 0.6 to 0.5 ) decreases the equilibrium rate of violence by one fifth and one fourth in the education and the feedback effect models to $14.4 \%$ and $9.2 \%$, respectively. Education has a smaller but still significant effect; a rise in the proportion of college graduates from 0.15 to 0.25 causes the equilibrium rate to drop by about $15 \%$ in both models (15.6\% and $10.2 \%$, respectively). On the other hand, the effect of matching based on similar history of family violence is surprisingly small. Even if we assume pure assortative mating $(\sigma=1)$, the change in the equilibrium rate is less than $0.5 \%$ in both models. Setting $\sigma=0$, and so dropping this assumption, decreases the domestic violence rate by only $0.9 \%$ and $0.6 \%$ in the education and feedback effect models respectively.

The results above obviously depend on the underlying parameter values. In order to elaborate the sensitivity of the results to the parameter value choices, we present two "extreme" cases, which are located close to the opposing ends of the range of parameter values (Table 2). Case I, with very high violence probabilities, almost no divorce and very low education levels, resembles a poor, traditional country with extreme male dominance over women. Case II, on the other hand, is similar to a developed country that has achieved gender equality.

Table 2

The Two Extreme Cases

\begin{tabular}{l|c|c|c|c|c|c|c}
\hline & $p_{v}$ & $p_{\bar{v}}$ & $s_{v}$ & $s_{\bar{v}}$ & $e$ & $\pi_{E}$ & $\pi_{F}$ \\
\hline Case I & 0.8 & 0.5 & 0.9 & 0.9 & 0.05 & $\mathbf{5 8 . 1 \%}$ & $\mathbf{6 3 . 4 \%}$ \\
\hline Case II & 0.3 & 0.1 & 0.5 & 0.3 & 0.25 & $\mathbf{2 . 6 \%}$ & $\mathbf{1 . 3 \%}$ \\
\hline
\end{tabular}


As can be seen in Table 2, the equilibrium rate for Case I is $58.1 \%$ for the education model and $63.4 \%$ for the feedback effect model. When the violence and no-divorce probabilities are very high, the feedback mechanism works to increase the violence rate; therefore the education model has a lower equilibrium value. These results would be close to the realistic upper limit of the model, although theoretically the rate of violence can rise to 1 if major parameter values except education approach 1 . On the other hand, Case II has very low domestic violence rates, $2.6 \%$ and $1.3 \%$. Values around these figures would constitute the practical lower limit to the model's predictions.

\section{Concluding Remarks}

In this paper we offer a reformulation of Pollak's model by incorporating the impact of education on domestic violence and the feedback relationship between the prevalence of violence in a society and men's likelihood to abuse their partners at home. We show that as the level of higher education increases in a society the level of domestic violence decreases. We also show that when there is a feedback relationship between the prevalence of domestic violence in the society and men's likelihood of using violence, wife abuse will decrease more because any fall in the rate of domestic violence will trigger a multiplier effect. We employ a numerical example at the end to support our findings.

The model has few direct policy implications, as Pollak also states, because the parameters of the model are not policy variables. Unlike rational agent models, there is no decision making here, thus we cannot argue how a particular policy measure would affect the incentives and/or constraints an individual decision maker faces. We do not analyze the contexts where decisions of going to college, choosing a spouse, using violence or leaving an abusive relationship are made. However, policy measures would decrease or increase the rate of violence as long as they cause changes in the probabilities of the model. Then, we can suggest ways in which policy affects the model's parameters. The numerical example shows that biggest gains in the fight against domestic violence will be reaped by making men less prone to violence and by helping wives leave abusive husbands. Making domestic violence a crime and prosecuting the perpetrators as well as running a nationwide multi-faceted public awareness campaign against violence would decrease the violence probabilities. Providing assistance to the victims in the forms of shelter, health care, legal advice and some form of short-term economic security would increase divorce probabilities by encouraging more women to escape from violence. Policies promoting women's empowerment and gender equality in general would increase women's options and weaken social norms legitimizing wife abuse, thus decreasing the rate of domestic violence in the model. Moreover, as college education becomes more available, the ratio of violent families would fall. Higher education is valuable on its own considering its contribution to human capital stock; however a suggestion to counter domestic violence by establishing more universities is not meaningful. Nevertheless, the positive externality created by college education is not insignificant. This effect can be strengthened in the developing countries by emphasizing more egalitarian gender relations in higher education; the campuses there, 
although ahead of their society, are still behind their Western counterparts in terms of a balance of power between the sexes.

\section{References}

Ackerson, L.K., Kawachi I., Barbeau E.M., and Subramanian S.V. (2008). "Effects of Individual and Proximate Educational Context on Intimate Partner Violence: A Population-Based Study of Women in India," American Journal of Public Health, 98: 507-514.

Aizer, A. (2010). "The Gender Wage Gap and Domestic Violence," American Economic Review, 100: $1847-1859$.

Altınay, A.G. and Arat, Y. (2007). Türkiye’de Kadına Yönelik Şiddet Araştırma Raporu, (Research on Violence against Women in Turkey). Ankara: Tübitak.

Anderson, K. L. (2010). "Conflict, Power, and Violence in Families," Journal of Marriage and the Family, 72: 726-742.

Blair Johnson, K. and Bordia Das, M. (2009). "Spousal Violence in Bangladesh as Reported by Men: Prevalence and Risk Factors," Journal of Interpersonal Violence, 24: 977-995.

Bloch, F. and Rao V. (2002). "Terror as a Bargaining Instrument: A Case Study of Dowry Violence in Rural India," American Economic Review, 92: 1029-1043.

Bobonis, G.J., Castro R., and Brenes, M.G. (2009). "Public Transfers and Domestic Violence: The Roles of Private Information and Spousal Control," Working Paper 362, University of Toronto, Department of Economics.

Bowlus, A.J. and Seitz, S. (2006). "Domestic Violence, Employment and Divorce," International Economic Review, 47: 1113-1149.

Burton, B., Duvvury, N., and Varia, N. (2000). Justice, Change, and Human Rights: International Research and Responses to Domestic Violence. Washington, DC: ICRW.

Carney, M., Buttell, F., and Dutton, D. (2007). "Women Who Perpetrate Intimate Partner Violence: A Review of the Literature with Recommendations for Treatment," Aggression and Violent Behavior, 12: $108-115$.

Cubbins, L. and Vannoy, D. (2005). "Socioeconomic Resources, Gender Traditionalism, and Wife Abuse in Urban Russian Couples," Journal of Marriage and the Family, 67: 37-52.

DeRiviere, L. (2008). "Do Economists Need to Rethink their Approaches to Modeling Intimate Partner Violence?," Journal of Economic Issues, 42: 583-606.

Dutton, D.G. (2006). Rethinking Domestic Violence. UBC Press: Vancouver.

Edleson, J.L. (1999). "The Overlap between Child Maltreatment and Woman Battering," Violence Against Women, 5: 134-154.

Ehrensaft, M.K., Cohen, P., Brown J., Smailes, E., Chen, H., and Johnson, J. (2003). "Intergenerational Transmission of Partner Violence: A 20-Year Prospective Study," Journal of Consulting and Clinical Psychology, 71: 741-753.

Ellsberg M., Heise, L., Pena, R., Agurto, S., and Winkwist, A. (2001). "Researching Domestic Violence Against Women: Methodological and Ethical Considerations," Studies in Family Planning, 32: 1-16.

Farmer, A. and Thiefenthaler, J. (1996). "Domestic Violence: The Value of Services as Signals," American Economic Review, 86: 274-279. 
García-Moreno, C., Jansen, H., Ellsberg, M., Helse, L., and Watts, C. (2005). WHO Multi-Country Study on Women's Health and Domestic Violence against Women: Initial Results on Prevalence, Health Outcomes and Women's Responses, Geneva: WHO Press.

Heyman, R. and Slep, A. (2002). "Do Child Abuse and Interparental Violence Lead to Adulthood Family Violence," Journal of Marriage and the Family, 64: 864-870.

Holt, S., Buckley, H., and Whelan, S. (2008). "The Impact of Exposure to Domestic Violence on Children and Young People: A Review of the Literature," Child Abuse and Neglect, 32: 797-810.

Hotaling, G. and Sugarman, D. (1986). "An Analysis of Risk Markers in Husband to Wife Violence: The Current State of Knowledge," Violence Victims, 1: 101-124.

Kingston-Riechers, J. (2001). "The Association between the Frequency of Wife Assault and Marital Dissolution in Canada," Journal of Population Economics, 14: 351-365.

Kishor, S. and Johnson, K. (2004). Profiling Domestic Violence - A Multi-Country Study. Calverton, Maryland: ORC Macro.

Koç, A. and Erkin, C. (2011). "Development, Women's Resources and Domestic Violence," in F. Morady and İ. Şiriner (eds.), Globalization, Religion and Development: 129-148. London: Ijopec

Krug, E.G., Mercj, J.A., Dahlberg, L., and Zwi, A.B. (2002). World Report on Violence and Health. Geneva: World Health Organization.

Kurtz, P.D., Gaudin, J.M., Wodarski, J.S., and Howing, P.T. (1993). "Maltreatment and the School Aged Child: School Performance Consequences," Child Abuse Neglect, 17: 581-89.

Leiter, J. and Johnsen, M.C. (1997). "Child Maltreatment and School Performance Declines: An Event-History Analysis," American Educational Research Journal, 34: 563-589.

Levinson, D. (1989). Family Violence in a Cross-cultural Perspective. Newbury Park: Sage.

Levinson, D. and Malone, M. (1980). Toward Explaining Human Culture: A Critical Review of the Findings of Worldwide Cross-Cultural Research. New Haven, CT: HRAF Press.

Loue, S. (2001). Intimate Partner Violence: Societal, Medical, Legal and Individual Responses. New York: Kluwer Academic/Plenium Publishers.

Lunkenheimer, E.S., Kittler, J.E., Olson, S.L., and Kleinberg, F. (2006). "The Intergenerational Transmission of Physical Punishment: Differing Mechanisms in Mothers' and Fathers' Endorsement?," Journal of Family Violence, 21: 509-519.

Margolin, G. and Gordis, E.B. (2000). "The Effects of Family and Community Violence on Children," Annual Review of Psychology, 51: 445-479.

Martina, S., Moracco, K.E., Garro, J., Tsui, A.O., Kupper, L.L., and Chase, J.L. (2002). "Domestic Violence across Generations: Findings from Northern India," International Journal of Epidemiology, 31: $560-572$.

Mihalic, S. and Elliott, D. (1997). “A Social Learning Theory Model of Marital Violence," Journal of Family Violence, 12: 21-47.

Morrison, A.R. and Orlando, M.B. (1999). "Social and Economic Costs of Domestic Violence: Chile and Nicaragua," in A.R. Morrison and M.L. Biehl (eds.), Too Close to Home: Domestic Violence in the Americas: 105-130. Washington: Inter-American Development Bank.

Page, A.Z. and İnce, M. (2008). “Aile İçi Şiddet Konusunda Bir Derleme,” Türk Psikoloji Yazıları, 11: 81-94. 
Panda, P. and Agarwal, B. (2005). "Marital Violence, Human Development and Women's Property Status in India," World Development, 33: 828-850.

Pollak, R.A. (2004). “An Intergenerational Model of Domestic Violence,” Journal of Population Economics, 17: 311-329.

Schwartz, C. and Mare, R. (2005). "Trends in Educational Assortative Marriage from 1940 to 2003," Demography, 42: 621-646.

Simons, R.L., Johnson, C., Beaman, J., and Conger, R.D. (1993). "Explaining Women's Double Jeopardy: Factors that Mediate the Association between Harsh Treatment as a Child and Violence by a Husband," Journal of Marriage and the Family, 55: 713-723.

Stith, S.M., Rosen, K.H., Middleton, K.A., Busch, A.L., Lundeberg, K., and Carlton, R.P. (2000). "The Intergenerational Transmission of Spouse Abuse: A Meta Analysis," Journal of Marriage and the Family, 62: 640-654.

Straus, M.A. (1979). "Family Patterns and Child Abuse in a Nationally Representative American Sample," Child Abuse and Neglect, 3: 213-225.

Straus, M.A. and Kantor, K. (1994). "Corporal Punishment by Parents: A Risk Factor in the Epidemiology of Depression, Suicide, Alcohol Abuse, Child Abuse and Wife Beating," Adolescence, 29: 543-561.

Swinford, S.P., DeMaris, A., Cernkovich, S.A., and Giordano, P.C. (2000). "Harsh Physical Discipline in Childhood and Violence in Later Romantic Involvements: The Mediating Role of Problem Behaviors," Journal of Marriage and the Family, 62: 508-519.

Tansel, A. (1999). "Türkiye ve Seçilmiş Ülkelerde Eğitimin Getirisi," (The Benefits of Education in Turkey and Selected Countries), METU Studies in Development, 26: 453-472.

Tauchen, H.V., Witte A.D., and Long, S.K. (1991). "Domestic Violence: A Nonrandom Affair," International Economic Review, 32: 491-511.

T.C. Başbakanlık Aile Araştırma Kurumu Başkanlığı, (2000). Aile İçi Şiddetin Sebep ve Sonuçları, (The Reasons and Results of Domestic Violence). Ankara.

Tjaden, P. and Thoennes, N. (2000). Extent, Nature, and Consequences of Intimate Partner Violence. Washington: National Institute of Justice.

Vyas, S. and Watts, C. (2009). "How does Economic Empowerment Affect Women's Risk of Intimate Partner Violence in Low and Middle Income Countries?," Journal of International Development, 21: 577-602.

Watts, C. and Zimmerman. C. (2002). "Violence against Women: Global Scope and Magnitude," Lancet, 359: 1232-1237.

Wodarski, J.S., Kurtz, P.D., Gaudin, J.M., and Howing, P.T. (1990). "Maltreatment and the Schoolaged Child: Major Academic, Socioemotional, and Adaptive Outcomes," Social Work, 35: 506-513.

Wolfgang, M. and Ferracuti, F. (1967). The Subculture of Violence: Toward an Integrated Theory of Criminology. London: Tavistoc. 